\title{
EXTIRPACIÓN DE CARCINOMA DE LABIO INFERIOR Y RECONSTRUCCIÓN MEDIANTE COLGAJO DE KARAPANDZIC. DESCRIPCIÓN DE UN CASO
}

\section{Removal of lower lip carcinoma and reconstruction by Karapandzic flap. Case report}

\author{
Pedro DÍAZ DE CERIO-CANDUELA; Sara OMEDES-SANCHO \\ Servicio de Otorrinolaringología. Hospital San Pedro. Logroño. España. \\ Correspondencia:pdiazcerio@gmail.com
}

Fecha de recepción: 6 de octubre de 2017

Fecha de aceptación: 19 de octubre de 2017

Fecha de publicación: 21 de octubre de 2017

Fecha de publicación del fascículo: 15 de marzo de 2019

Conflicto de intereses: Los autores declaran no tener conflictos de intereses

Imágenes: Los autores declaran haber obtenido las imágenes con el permiso de los pacientes

Política de derechos y autoarchivo: se permite el autoarchivo de la versión post-print (SHERPA/RoMEO)

Licencia CC BY-NC-ND. Licencia Creative Commons Atribución-NoComercial-SinDerivar 4.0 Internacional

Universidad de Salamanca. Su comercialización está sujeta al permiso del editor

RESUMEN: Introducción: El carcinoma de labio inferior es una enfermedad relativamente frecuente que precisa tratamiento quirúrgico para su resolución. La reconstrucción del defecto quirúrgico cobra importancia a la hora de preservar las funciones de la cavidad oral y la estética facial. Descripción: presentamos un paciente con carcinoma de labio inferior que requiere una amplia exéresis y su reconstrucción mediante un colgajo de Karapandzic. Conclusiones: La reconstrucción del labio inferior mediante la realización de un colgajo de Karapandzic permite la exéresis de tumores extensos de labio inferior con la preservación de las funciones del mismo y unos resultados estéticos excelentes.

PALABRAS CLAVE: Cáncer de labio; reconstrucción de labio inferior; colgajo de Karapandiz

SUMMARY: Introduction: Lower lip carcinoma is a relatively frequent disease, it needs surgical treatment for its resolution. The reconstruction of the surgical defect is very important because it comes to preserving the oral cavity functions and facial aesthetical. Description we present a case-patient with a lower lip carcinoma that requires extensive excision and its reconstruction by a Karapandzic flap. Discussion: The 


\section{EXTIRPACIÓN DE CARCINOMA DE LABIO INFERIOR Y RECONSTRUCCIÓN MEDIANTE COLGAJO DE KARAPANDZIC. DESCRIPCIÓN DE UN CASO DÍAZ DE CERIO-CANDUELA P Y OMEDES-SANCHO S}

reconstruction of the lower lip by a Karapandzic flap realization allows the excision of big tumors of the lower lip with the preservation of the oral cavity functions and excellent aesthetical results.

KEYWORDS: Lip cancer; lower lip reconstruction; Karapandiz flap

\section{INTRODUCCIÓN}

El carcinoma de labio es una enfermedad relativamente frecuente, se estima que su incidencia es aproximadamente del 0,4 al 1\% [1], suponiendo cerca del 2\% de los tumores malignos de cabeza y cuello [2]. El 90\% de los casos se localiza en el labio inferior [3] y se relaciona con factores de riesgo como la exposición solar prolongada, el tabaco y el alcoholismo crónico. El 95\% de las estirpes tumorales corresponden a carcinoma epidermoide y la relación hombre/mujer suele ser de 9:1. El diagnóstico se realiza por lo general en estadios precoces (T1 y T2), siendo su pronóstico en estos estadios superior al $90 \%$ a los 5 años, según las series [4]. Aunque las metástasis ganglionares cervicales son poco frecuentes, dependen del tamaño tumoral y de la localización anatómica del tumor, siendo más frecuentes si se localiza cerca de la comisura de la cavidad oral. El tratamiento es habitualmente quirúrgico, en los casos en los que se afecte menos del 25\% de la superficie del labio inferior se puede realizar una exéresis en cuña con cierre simple del defecto. En cambio, los tumores de labio inferior que afectan a más de un $75 \%$ de la superficie del mismo requieren de reconstrucciones más complejas, precisando la realización de colgajos de avance y rotación que garanticen el cierre del defecto y la preservación de las funciones de los labios junto con el mejor resultado estético posible. De entre los distintos tipos de colgajos de reconstrucción existentes [5], el colgajo descrito por Karapandzic en 1974 [6] se ajusta perfectamente a las necesidades anteriormente descritas de mantenimiento de la función de la cavidad oral junto con un excelente resultado estético.

Ediciones Universidad de Salamanca / ㅇ@

[ 80 ]

\section{DESCRIPCIÓN}

Se presenta el caso de un paciente varón de 71 años que presentaba una lesión en labio inferior de varios meses de evolución, excrecente, friable y sangrante a mínimo (Figura 1). Como antecedentes personales destacaba el haber trabajado expuesto a la radiación solar como personal de mantenimiento de instalaciones deportivas y el consumo de tabaco y alcohol.

La lesión medía aproximadamente $4 \mathrm{~cm}$ de longitud total y afectaba a más del $75 \%$ de la superficie total del labio inferior. Una biopsia preoperatoria confirmó el diagnóstico de carcinoma epidermoide. Tras la realización de una tomografía axial computadorizada de cabeza y cuello y tórax y constatar la ausencia de metástasis ganglionares cervicales y a distancia, se clasificó el tumor como cT2N0M0 según la clasificación de la American Joint Committee on Cancer (AJCC). Se realizó exéresis tumoral, vaciamiento funcional de las áreas ganglionares I a III bilaterales y reconstrucción del defecto mediante la realización de un colgajo de Karapandzic, según indica la guía de la National Comprehensive Cancer Network [7].

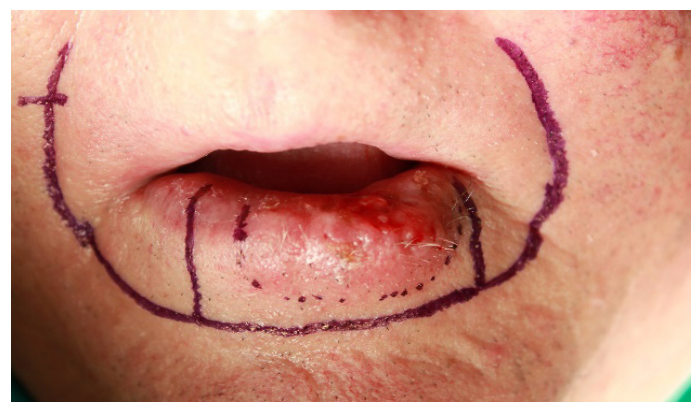

Figura 1. Tumor primario de labio inferior. 


\section{EXTIRPACIÓN DE CARCINOMA DE LABIO INFERIOR Y RECONSTRUCCIÓN \\ MEDIANTE COLGAJO DE KARAPANDZIC. DESCRIPCIÓN DE UN CASO \\ DÍAZ DE CERIO-CANDUELA P Y OMEDES-SANCHO S}
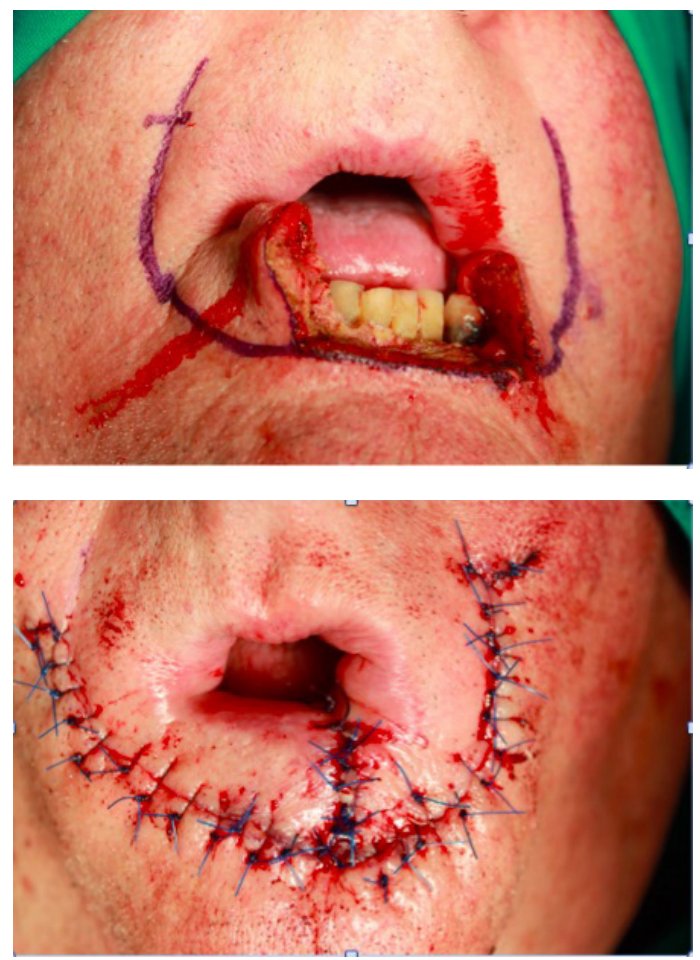

Figura 2. Exéresis tumoral, diseño del colgajo y sutura del mismo.

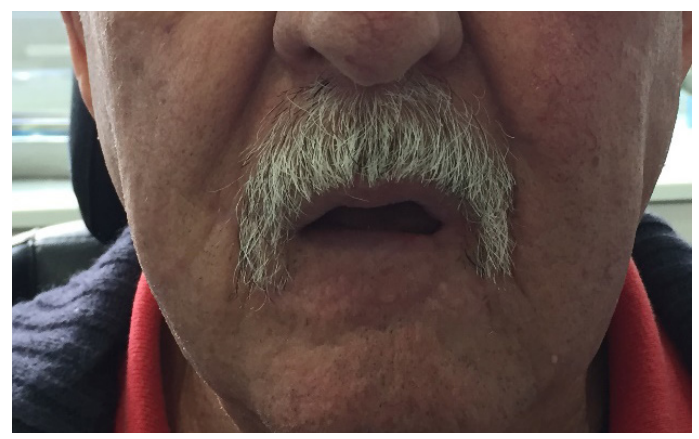

Figura 3. Resultado a los 3 meses de la cirugía.

La exéresis del tumor de labio inferior junto con los márgenes de seguridad adecuados ofrecía un defecto de superficie cuadrangular cercano al $80 \%$ de la superficie total del labio inferior, que se reconstruyó cuidadosamente para preservar la estética facial y las funciones de los labios (Figura 2).

El resultado definitivo de la anatomía patológica de la pieza quirúrgica confirmó el diagnóstico de carcinoma epidermoide de labio inferior pT2N0M0, no necesitándose de esta manera la utilización de tratamiento oncológico adyuvante. La revisión del paciente a los tres meses de la cirugía confirmó un resultado estético excelente y un resultado funcional completamente normal, permitiéndole la vocalización y la alimentación por vía oral sin ningún tipo de impedimento (Figura 3).

\section{DISCUSIÓN}

El colgajo de reconstrucción de labio inferior diseñado por Karapandzic se basa en la movilización de la piel y de las partes blandas de la porción inferior de la región nasolabial. Estos tejidos son rotados hacia la línea media del defecto quirúrgico de tal manera que el músculo orbicular de los labios se mantiene inervado e irrigado neuromuscularmente mediante la arteria labial inferior y las terminaciones nerviosas seccionadas en el tiempo de la exéresis quirúrgica, conservando con ello la funcionalidad y competencia de la cavidad oral. La técnica para la realización del colgajo de Karapandzic empieza una vez realizada la exéresis tumoral. En primer lugar, se procede a la ampliación de la incisión inicial en sentido ascendente hacia el pliegue nasogeniano, dejando cierta curvatura para preservar la estética [8]. Es importante realizar una incisión de descarga dentro de la mucosa interna de la cavidad oral sin llegar a la musculatura y paralela a la incisión cutánea del colgajo para facilitar el desplazamiento del mismo. Posteriormente se inicia el cierre mucoso, muscular y cutáneo del colgajo con la alineación exacta de los músculos orbiculares de los labios seccionados en el primer tiempo quirúrgico para facilitar el movimiento del labio en la recuperación posterior. Los puntos de sutura se dan con hilo de material no reabsorbible en piel y con hilo de material reabsorbible en las 


\section{EXTIRPACIÓN DE CARCINOMA DE LABIO INFERIOR Y RECONSTRUCCIÓN MEDIANTE COLGAJO DE KARAPANDZIC. DESCRIPCIÓN DE UN CASO DÍAZ DE CERIO-CANDUELA P Y OMEDES-SANCHO S}

zonas de mucosa de labio y de cavidad oral. Se deben dar numerosos puntos de sutura ya que la tensión propia de la boca y sus movimientos pueden provocar fácilmente una dehiscencia de la sutura, retrasando la cicatrización, alterando el resultado estético y funcional definitivo, obligando en estos casos a volver a suturar el defecto (Figura 2). Es recomendable dejar una sonda nasogástrica para alimentación durante 7 días aproximadamente para evitar la sobreinfección y la dehiscencia de suturas, aunque no es imprescindible.

Los carcinomas de labio inferior constituyen una enfermedad relativamente frecuente dentro de los tumores que afectan a la cabeza y el cuello. Su pronóstico en estadios iniciales, que suele ser el momento más frecuente de diagnóstico, alcanza unas elevadas tasas de supervivencia a los 5 años. El problema surge en la reparación estética y funcional del labio inferior. Al tratarse de una zona muy visible dentro de la cara adquiere una gran importancia realizar una reconstrucción que deje un resultado estético óptimo. Además de ello, el labio inferior es una estructura que adquiere gran importancia funcional a la hora de la alimentación y de la propia articulación de la palabra y que se debe tener presente a la hora de la reparación quirúrgica tanto o más que el resultado estético.

De entre las distintas técnicas existentes para la reconstrucción quirúrgica de los defectos de labio inferior que superen el $80 \%$ del mismo, el colgajo diseñado por Karapandzic resulta ser el más adecuado. Su fácil técnica hace que pueda ser fácilmente reproducible en casi cualquier paciente. El tiempo quirúrgico necesario para su realización es habitualmente escaso y la recuperación del paciente suele necesitar de una hospitalización corta y de pocos días para reiniciar la alimentación por vía oral, en algunos casos incluso inmediata. Los resultados tanto estéticos como funcionales son muy satisfactorios a las pocas semanas de la realización de la intervención.

\section{CONCLUSIONES}

El colgajo de Karapandzic es adecuado para la reconstrucción de defectos de labio inferior que afecten una gran superficie del mismo.

\section{BIBLIOGRAFÍA}

1. Campos MA, Varela P, Marques C. Near-total lower lip reconstruction: combined Karapandzic and Bernard-Burrow-Webster flap. Acta Dermatovenerol APA. 2017;26:19-20.

2. Beauvillain de Metreuil C, Drèno B, Tessier MH. Tumeurs bènignes et malignes del lèvres. Encycl Méd Chir (editions Scientifiques el Médicales Elservier SAS), Paris, Oto-rhino-laryngologie, 20-625-A-10. 1998. 14p.

3. Ebrahimi A, Kalantar Motamedi MH, Ebrahimi A, Kazemi M, Shams A, Hashemzadeh H. Lip Reconstruction after Tumor Ablation. World J Plast Surg. 2016;5(1):15-25.

4. Song JI. Cancer of the lip. En: Myers EN, Ferris $\mathrm{RL}$, editores. Master tecniques in otolaryngology Head and Neck Surgery. Editorial Wolters-Kluwer; 2014. p 1-8.

5. Filimon S, Richardson K, Hier MP, Roskies M, Mlynarek AM. The use of a modified abbé island flap to reconstruct primary lip defects of over 80 . J Otolaryngol Head Neck Surg. 2016;45(1):35.

6. Karapandzic M. Reconstruction of lip defects by local arterial flaps. Br J Plast Surg. 1974;27:93-7.

7. NCCN Guideliness. National Comprehensive Cancer Network. Head and Neck Cancers. (version 2.2017). Disponible en: https://www.nccn.org/ professionals/physician_gls/pdf/head-and-neck. pdf. [Citado el 19 de octubre de 2017].

8. Shah J. Los labios. En: Shah J. Cirugía y oncología de cabeza y cuello. $3^{\text {a }}$ edición. Madrid: editorial Elsevier España; 2004. p 149-172. 